\title{
HUBUNGAN FAKTOR LINGKUNGAN SOSIAL DENGAN IDE BUNUH DIRI PADA REMAJA DI KABUPATEN MINAHASA PROVINSI SULAWESI UTARA
}

\author{
Galatia Marline Victoria Rantung ${ }^{a^{*}}$, Damajanty H. C. Pangemanan ${ }^{b}$, Hendro J. Bidjuni ${ }^{\mathrm{c}}$ \\ ${ }^{a}$ Mahasiswa Program Studi Ilmu Keperawatan Fakultas Kedokteran Universitas Sam \\ Ratulangi \\ ${ }^{\mathrm{b}}$ Dosen Fakultas Kedokteran Universitas Sam Ratulangi \\ ${ }^{c}$ Dosen Program Studi Ilmu Keperawatan Fakultas Kedokteran Universitas Sam Ratulangi \\ *Email: marline.rantung3003@gmail.com
}

\begin{abstract}
Background: Suicide occurs at all ages and is the second leading cause of death among the ages of 15-29 globally. The idea of suicide arises in psychiatric emergencies since the individual is in a high level of stress while using the wrong adjustment mechanism. The environmental of family and friends is one of the risk factors for the occurrence of suicide in adolescents. Aim: To know the correlation between factors of the social environment with adolescent suicide ideation. Methods: This is a quantitative study with the Cross Sectional approach. Data collecting is done using a questionnaire. This study used total sampling of 156 respondents. This study used the Chi-square test. Results: Above 54\% of respondents had high suicidal ideation. Statistical test result of the family environmental factors with suicide ideation showed that value of $p=0,206(>\alpha=0,05)$ and result of the friendship environmental factors with suicide ideation showed that value of $p=0,699(>\alpha=0,05)$. Most respondents with high or low suicidal ideation have high support from social environment of family and friends. Conclusion: There is no correlation between factors of the social environtment with adolescent suicide ideation.
\end{abstract}

Keywords: Social Environment, Suicide Ideation

\begin{abstract}
Abstrak
Latar Belakang: Bunuh diri terjadi sepanjang umur dan merupakan penyebab utama kematian kedua di antara anak usia 15-29 tahun secara global. Ide bunuh diri muncul pada keadaan darurat psikiatri karena individu berada dalam keadaan stres yang tinggi dan menggunakan mekanisme penyesuaian diri yang salah. Lingkungan keluarga dan teman merupakan salah satu faktor resiko penyebab terjadinya bunuh diri pada remaja. Tujuan: Mengetahui hubungan faktor lingkungan sosial dengan ide bunuh diri pada remaja. Metode: Jenis penelitian ini menggunakan penelitian kuantitatif dengan pendekatan cross sectional. Metode pengumpulan data pada penelitian ini menggunakan kuesioner. Sampel penelitian menggunakan total sampling sebanyak 156 responden remaja kelas XI di salah satu SMK Negeri. Data analisis penelitian ini menggunakan uji statistik Chi-square. Hasil: Sebanyak $54 \%$ responden memiliki ide bunuh diri yang tinggi. Uji statistik faktor lingkungan sosial keluarga dengan ide bunuh diri diperoleh nilai $\mathrm{p}=0,206(>\alpha=0,05)$ dan uji statistik faktor lingkungan sosial teman dengan ide bunuh diri diperoleh nilai $p=0,699(>\alpha=0,05)$. Sebagian besar responden dengan ide bunuh diri yang tinggi maupun rendah memiliki dukungan dari faktor lingkungan sosial keluarga dan teman yang tinggi. Simpulan: Hasil penelitian ini menunjukkan tidak ada hubungan antara faktor lingkungan sosial keluarga dan teman dengan ide bunuh diri pada remaja.
\end{abstract}

Kata Kunci: Lingkungan Sosial, Ide Bunuh Diri 


\section{PENDAHULUAN}

Remaja merupakan salah satu populasi terbesar didunia. Masa remaja adalah masa transisi dimana seseorang belum dikatakan dewasa namun bukan anak-anak (Stuart, 2013). Banyak perubahan terjadi pada fase remaja seperti perubahan biologis, psikologis, maupun sosial (Indarjo, 2009). Remaja harus menghadapi perubahan fisik, kognitif, dan emosional yang dapat menimbulkan stress dan memicu perilaku unik pada remaja (Stuart, 2013).

Bunuh diri adalah penyebab utama kematian, melebihi jumlah pembunuhan atau kematian terkait perang.Sebagian besar orang dengan ide, rencana, dan percobaan bunuh diri tidak mendapat pengobatan (Keliat, 2015).

Data yang di dapat oleh World Health Organization (WHO) pada tahun 2015 hampir 800.000 kasus orang meninggal karena bunuh diri setiap tahunnya, yang merupakan satu orang setiap 40 detik. Bunuh diri terjadi sepanjang umur dan merupakan penyebab utama kematian kedua di antara anak usia 15-29 tahun secara global. Data yang dilaporkan oleh World Health Organization (WHO) pada tahun 2010 angka bunuh diri di Indonesia mencapai 1,6 hingga 1,8 persen dari 100.000 jiwa (Mardani, 2012).

Banyak faktor resiko bunuh diri pada remaja diantaranya: faktor psikologis, faktor keluarga, faktor lingkungan, faktor biologis, perilaku bunuh diri sebelumnya dan orientasi seksual (Stuart, 2013).

Hasil data awal dengan melakukan wawancara pada guru dan siswa-siswi sebanyak 15 orang didapatkan beberapa siswa merasa kurang untuk berkomunikasi dengan orang tua ketika mengalami masalah dan belum mendapatkan orangorang spesial yang ada di sekitar ketika mereka membutuhkan. Hasil wawancara dengan guru di temukan bahwa ada beberapa kasus yang melibatkan beberapa siswa di sekolah tersebut seperti kasus percobaan bunuh diri yang dilakukan siswa namun di ketahui terlebih dahulu orang tua sehingga digagalkan, terdapat juga kasus bunuh diri karena masalah hubungan dengan orang terdekat. Oleh karena itu tujuan penelitian ini adalah untuk mengetahui hubungan faktor lingkungan sosial dengan ide bunuh diri pada remaja.

\section{METODE}

Penelitian ini menggunakan jenis penelitian kuantitatif dengan pendekatan cross sectional. Penelitian ini dilakukan di Sebuah SMK Negeri di Kabupaten Minahasa Provinsi Sulawesi Utara. Populasi pada penelitian ini adalah siswasiswi kelas XI yaitu sebanyak 156 orang. Sampel pada penelitian ini menggunakan total sampling yaitu sebanyak 156 responden.

Instrumen penelitian yang digunakan pada penelitian ini yaitu kuesioner ide bunuh diri yang diadopsi dari penelitian Aulia Nur, tahun 2016 dan sudah di lakukan uji validitas dan reliabilitas. Uji validitas pada instrument ini memiliki nilai $\mathrm{r}$ hitung $>$ dari $\mathrm{r}$ table $=0,361$, uji reliabilitas pada instrumen ini nilai cronbach's alpha $=0,913$. Kuesioner ini terdiri dari 19 pertanyaan dengan nilai 0,1 , dan 2 untuk skornya dihitung dengan cara menjumlahkan setiap nilai dengan skor minimal 0 dan maksimal 38 .

Instrumen penelitian kuesioner faktor lingkungan sosial keluarga merupakan kuesioner yang dibuat oleh peneliti sendiri dan telah dilakukan uji validitas dan reliabilitas. Uji validitas pada instrument ini memiliki nilai $\mathrm{r}$ hitung $>$ dari $\mathrm{r}$ table $=$ 0,4227, uji reliabilitas pada instrument ini nilai cronbach's alpha $=0,894$. Kuesioner ini terdiri dari 10 pernyataan dengan menggunakan skala likert dengan ketentuan pemberian skor sangat setuju 5, setuju 4, ragu-ragu 3, tidak setuju 2, sangat tidak setuju 1.

Instrumen penelitian kuesioner faktor lingkungan sosial teman merupakan kuesioner yang dibuat oleh peneliti sendiri dan telah dilakukan uji validitas dan reliabilitas. Uji validitas pada instrument ini memiliki nilai $\mathrm{r}$ hitung $>$ dari $\mathrm{r}$ table $=$ 0,4227 , uji reliabilitas pada instrument ini 
nilai cronbach's alpha $=0,795$. Kuesioner ini terdiri dari 10 pernyataan dengan menggunakan skala likert dengan ketentuan pemberian skor sangat setuju 5, setuju 4, ragu-ragu 3, tidak setuju 2, sangat tidak setuju 1.

Analisis penelitian ini menghubungkan variabel independen dan dependen dengan menggunakan uji Chi-Square dengan $\alpha<0,05$.

Pada penelitian ini peneliti menggunakan etika penelitian yang bertujuan untuk menjaga kerahasiaan identitas responden agar hak-hak responden tetap dihormati dan tidak memaksakan kehendak melainkan karena keinginan responden sendiri. Penelitian ini juga telah memiliki izin penelitian dari pihak sekolah tempat dilakukannya penelitian dengan nomor izin surat Nomor: 058/116.17.9/SMK 1/KP/2021 dan dari respondennya sendiri.

\section{HASIL}

\section{Data Analisis Univariat}

Tabel 1. Distribusi frekuensi responden berdasarkan karakteristik responden

\begin{tabular}{lcc}
\hline Karakateristik Responden & F & \% \\
\hline Usia (tahun) & & 18 \\
15 & 28 & 46 \\
16 & 72 & 36 \\
17 & 56 & \\
\hline Jenis Kelamin & & 46 \\
Perempuan & 71 & 54 \\
Laki-laki & 85 & \\
\hline
\end{tabular}

Sumber: Data Primer, 2021

Berdasarkan tabel 1, distribusi responden berdasarkan usia terbanyak adalah 16 tahun yaitu 72 responden (46\%) dan usia paling sedikit sedikit adalah usia 15 tahun yaitu 28 responden (18\%).
Menurut jenis kelamin distribusi responden yang berjenis kelamin laki-laki sebanyak 71 responden $(46 \%)$ dan perempuan sebanyak 85 responden $(54 \%)$.

Tabel 2. Distribusi responden berdasarkan ide bunuh diri, faktor lingkungan sosial keluarga, faktor lingkungan sosial teman

\begin{tabular}{lcc}
\hline Ide Bunuh Diri & F & \% \\
\hline Tinggi & 84 & 54 \\
Rendah & 72 & 46 \\
\hline Faktor Keluarga & & \\
\hline Tinggi & 95 & 61 \\
Rendah & 61 & 39 \\
\hline Faktor Teman & & \\
\hline Tinggi & 100 & 64 \\
Rendah & 56 & 36 \\
\hline
\end{tabular}

Sumber: Data Primer, 2021

Berdasarkan tabel 2, distribusi responden berdasarkan ide bunuh diri yang tinggi dari responden sebanyak 84 responden $(54 \%)$ sedangkan ide bunuh diri yang rendah dari responden sebanyak 72 responden (46\%). Menurut distribusi responden berdasarkan faktor lingkungan sosial keluarga yang tinggi sebanyak 95 responden $(61 \%)$ sedangkan faktor lingkungan sosial keluarga yang rendah 
sebanyak 61 responden (39\%). Menurut distribusi responden berdasarkan faktor lingkungan sosial teman yang tinggi sebanyak 100 responden (64\%) sedangkan faktor lingkungan sosial teman yang rendah sebanyak 56 responden (36\%).

Data Analisis Bivariat

Tabel 3. Analisis Hubungan Faktor Lingkungan Sosial (Faktor Keluarga dan Faktor Teman) dengan Ide Bunuh Diri Pada Remaja.

\begin{tabular}{|c|c|c|c|c|}
\hline \multirow{2}{*}{$\begin{array}{c}\text { Faktor } \\
\text { Keluarga }\end{array}$} & \multicolumn{2}{|c|}{ Ide Bunuh Diri } & \multirow{2}{*}{ Total } & \multirow[b]{2}{*}{$\mathbf{P}$} \\
\hline & Tinggi & Rendah & & \\
\hline Tinggi & 55 & 40 & 95 & \multirow{2}{*}{0,206} \\
\hline Rendah & 29 & 32 & 61 & \\
\hline Faktor & \multicolumn{2}{|c|}{ Ide Bunuh Diri } & & \\
\hline Teman & Tinggi & Rendah & Total & $\mathbf{P}$ \\
\hline Tinggi & 55 & 45 & 100 & 0,699 \\
\hline
\end{tabular}

Sumber: Data Primer, 2021

Berdasarkan tabel 3 diatas hasil analisis data yang dilakukan dengan uji statistic Chi-Square didapatkan nilai $\mathrm{p}=$ $0,206>0.05$ (nilai $\alpha$ ), maka Ha ditolak.

Hasil analisis data yang dilakukan dengan uji statistic Chi-Square didapatkan nilai $\mathrm{p}=0,699>0.05$ (nilai $\alpha$ ), maka Ha ditolak.

\section{PEMBAHASAN}

\section{Analisa Bivariat}

Hubungan Faktor Lingkungan Sosial (Faktor Keluarga) dengan Ide Bunuh Diri Pada Remaja

Hasil penelitian menunjukan sebagian besar responden dengan faktor lingkungan sosial keluarga tinggi memiliki ide bunuh diri tinggi dan sebagian responden yang memiliki ide bunuh diri rendah juga memiliki faktor lingkungan sosial keluarga yang tinggi.

Penelitian yang mendukung penelitian ini yaitu tidak terdapat hubungan faktor keluarga dengan ide bunuh diri pada remaja. Faktor dukungan sosial juga tidak memiliki pengaruh yang signifikan secara statistik terhadap percobaan bunuh diri dan tidak ada hubungan yang signifikan antara ide bunuh diri pada remaja dengan rasa kesepian (Nur, dkk).

Faktor lingkungan sosial keluarga ini tidak memiliki hubungan yang signifikan dimana pada remaja dengan keluarga yang memiliki disfungsi dan riwayat bunuh diri keluarga memiliki ide bunuh diri yang tinggi, sama seperti keluarga yang tidak memiliki disfungsi dan riwayat bunuh diri keluarga. Selain itu tidak ada hubungan yang signifikan juga antara ide bunuh diri pada remaja yang merasa kesepian karena orang tua bercerai. Remaja yang mendapatkan dukungan sosial yang kurang dari keluarga akan menyebabkan peningkatan terhadap ide untuk melakukan bunuh diri, ketika berada dalam kondisi stress (Nur, dkk).

\section{Hubungan Faktor Lingkungan Sosial (Faktor Teman) dengan Ide Bunuh Diri Pada Remaja.}

Hasil penelitian menunjukan sebagian besar responden dengan faktor lingkungan sosial teman tinggi memiliki ide bunuh diri yang tinggi dan sebagian responden yang memiliki ide bunuh diri rendah juga memiliki faktor lingkungan sosial teman yang tinggi.

Penelitian sebelumnya yang mendukung penelitian ini yaitu faktor lingkungan sosial tidak memiliki hubungan yang signifikan dengan ide bunuh diri remaja, selain itu relasi dengan teman dan sahabat tidak memiliki pengaruh yang signifikan secara statistik terhadap percobaan bunuh diri dan tidak terdapat 
hubungan antara ide bunuh diri dan keterampilan sosial (Nur, dkk).

Faktor lingkungan sosial teman ini tidak memiliki hubungan yang signifikan dimana ide bunuh diri yang tinggi lebih banyak terjadi pada remaja yang memiliki faktor lingkungan sosial yang baik, sedangkan faktor yang memiliki hubungan paling erat dengan ide bunuh diri adalah faktor psikologis, selain itu Hal ini disebabkan karena adanya variabel lain yang menjadi mediator antara idebunuh diri dan keterampilan sosial yaitu depresi dan terdapat faktor resiko lain seperti lingkungan keluarga, psikologis, dan lingkungan sekitar. Ditemukan bahwa seluruh sampel remaja pada penelitian memiliki tingkat ide bunuh diri yang rendah yang bisa disebabkan karena norma sosial dan agama menjadi faktor proteksi dari keinginan atau ide bunuh diri. Remaja memiliki respon yang sehat terhadap lingkungan yang menimbulkan stress, dimana remaja memiliki kemampuan untuk bertahan dalam kondisi yang kurang menguntungkan atau penuh tekanan, maka hal ini juga sangat berpengaruh terhadap munculnya ide bunuh diri dibandingkan faktor lingkungan sosial teman (Nur, dkk).

\section{SIMPULAN}

Tidak terdapat hubungan antara faktor lingkungan sosial keluarga dan teman dengan ide bunuh diri pada remaja. Oleh karena itu diharapkan pelayanan kesehatan lebih meningkatkan informasi tentang faktor-faktor lingkungan sosial guna untuk mencegah munculnya ide bunuh diri pada remaja. Implikasi penelitian ini bagi praktik keperawatan yaitu sebagai bahan informasi, masukan dan pengetahuan tentang faktor lingkungan sosial terhadap ide bunuh diri pada remaja dalam memberikan pelayanan kesehatan.

\section{DAFTAR PUSTAKA}

Adam, M. (2012). Kajian Bunuh Diri. Slide Share E-book
Alya, M. W. (2017). Faktor Yang Mempengaruhi Percobaan Bunuh Diri Pada Santri Di Pesantren X, Bogor

Asrori, M. (2008).Psikologi Pembelajaran. Bandung: CV. Wacana Prima

Aulia Nur. (2016). Analisis Hubungan Faktor Risiko Bunuh Diri Dengan Ide Bunuh Diri Pada Remaja Dikota Rengat Kabupaten Indragiri Hulu Tahun

2016.http://scholar.unand.ac.id/1315 4/5/Tesis\%20Lengkap\%20Aulia.pdf

Fortinash, \& Worret, H. (2012).Psychiatric Mental Health Nursing. St. Louis: Elsevier

Illiyyin, T. M. (2020). Problem Dan Ide Bunuh Diri Pada Mahasiswa

Indarjo, S. 2009. Kesehatan jiwa remaja.Jurnal kesehatan masyarakat.http://journal.unnes.ac.id lindex.php/kema

Jahja, Yudrik. 2011. Psikologi Perkembangan. Kencana Prenada Media Group. Jakarta.

Jeli, P \& Anna, U. (2014).Suicide Ideation Pada Remaja Di Kota Semarang

Julistya, F \& Marty, M. (2019).Keterampilan Sosial Berhubungan Dengan Ide Bunuh Diri: Studi Kasus Di Bener Meriah, Aceh

Kania, F. P (2019).Tingkat Resiliensi Dengan Ide Bunuh Diri Pada Remaja

Keliat, B.A. (2015). Keperawatan Kesehatan Jiwa Stuart. Jakarta: Elsevier

KPAI. (2014).

Linda, M (2020). Tingkat Depresi Dengan Ide Bunuh Diri Pada Remaja

Lita, A. K. D \& Hamidah (2013).Hubungan Antara Kesepian Dengan Ide Bunuh Diri Pada Remaja Dengan Orang Tua Yang Bercerai

Mardani. (2012, Juni 02). Kasus Bunuh Diri di Indonesia Sudah Memprihatinkan. Merdeka.com: http://www.merdeka.com/tag/b/bunu 
h-diri/kasus-bunuh-diri-di-indonesiasudah-memprihatinkan/ diakses: 13 Februari 2018

Muhith, A. (2015). Pendidikan Keperawatan Jiwa (Teori Dan Aplikasi). Yogyakarta: Andi

Notoatmodjo. 2010. Metodologi Penelitian Kesehatan. Rineka Cipta. Jakarta

Nur Aulia, dkk. (2019). Analisis Hubungan Faktor Risiko Bunuh Diri Dengan Ide Bunuh Diri Pada Remaja

Patel, S. C \& Jakopac, K. A. (2012).Manual of Psychiatric Nursing Skills. USA: Jones \& Barlet Learning

Salsabhilla, A \& Panjaitan, R. U. (2019).Dukungan Sosial Dan Hubungan Dengan Ide Bunuh Diri Pada Mahasiswa Rantau. Jurnal Keperawatan Jiwa,7 (1), 107.https://doi.org/10.1207/s153277 52jpa5602_9

Setiadi. 2013. Konsep dan Praktik Penulisan Riset Keperawatan (ed.2). Graha Ilmu. Yogyakarta.

Stuart, W. G. 2013. Prinsip dan praktik keperawatan kesehatan jiwa stuart vol $1 \& 2$. Singapore: Elsevier

Sunarti, N. (2012). Tipe Kepribadian, Tingkat Pendidikan, Status Social Ekonomi Dan Ide Bunuh Diri.file:///D:/PROPOSAL/Naskah Publikasi.pdf . Diakses: 4 September 2018

Suryanti, S.T. (2017). Pengaruh Lingkungan Sekolah Dan Lingkungan Teman Sebaya Terhadap Motivasi Melanjutkan Pendidikan Ke Perguruan Tinggi Pada Siswa MAN Purwoasari Kabupaten Kediri Tahun Ajaran 2016/2017.

Wahyu, B. N. (2012). Pemuda, Bunuh Diri dan Resiliensi: Penguatan Resiliensi sebagai Peredukasi Angka Bunuh Diri di Kalangan Pemuda Indonesia

WHO. (2015). Mental Health. Quality of suicide mortality data .Website : http://www.who.int/mental_health/pr evention/suicide/wspd/en/ diakses: 13 Februari 2018

Widianti, Efri. Remaja Dan Permasalahanny: Bahaya Merokok, Penyimpangan Seks Pada Remaja Dan Bahaya Penyalahgunaan Minuman Keras. http://resource.unpad.ac.id/unpadcon tent/uploac/publikasi_dosen/1A\%20 makalah.remaja\&masalahnya.pdf. Diakses: 06 desember 2018

Woelandarie, A.M. 2017. Factor Yang Mempengaruhi Percobaan Bunuh Diri Pada Santri Di Pesantren X, Bogor.

Yosep, H.I., \& Titin, S. (2014). Buku Ajar Keperawatan Jiwa Dan Advance Mental Health Nursing Cetakan Keenam. PT Refika Aditama: Bandung

Yosep, I. (2013). Keperawatan Jiwa. PT Refika Aditama: Bandung 